www.jmscr.igmpublication.org

Impact Factor 5.84

Index Copernicus Value: 71.58

ISSN (e)-2347-176x ISSN (p) 2455-0450

crossref DOI: _https://dx.doi.org/10.18535/jmscr/v5i12.129

Journal Of Medical Science And Clinical Research

IGM Publication

An Official Publication of IGM Publication

\title{
Preoperative Skin Preparation with Chlorhexidine Alcohol and Povidone Iodine: A Comparative Study
}

\author{
Authors \\ Ragesh Kalikkottu Valappil ${ }^{1}$, Perumbrayoor Thacharampurathu Sajesh ${ }^{2}$, \\ Sheena Krishnan ${ }^{3 *}$ \\ ${ }^{1}$ Department of Surgery, Government Medical College, Kozhikode, Kerala, India \\ ${ }^{2}$ Department of Surgery, Government Medical College, Kozhikode, Kerala, India \\ ${ }^{3}$ Department of Microbiology, Government Medical College, Kozhikode, Kerala, India \\ *Corresponding Author \\ Sheena Krishnan \\ Department of Microbiology, Government Medical College, Kozhikode, Kerala, India \\ Mobile Number: +919847193171, Email: kalikkot@gmail.com
}

\begin{abstract}
Background: Surgical Site Infections are the third most commonly reported nosocomial infections all over the world ${ }^{l}$. Patient's skin is a major source of pathogens that cause Surgical Site Infection. PovidoneIodine (5\%) is being used for preoperative skin preparation in surgeries since 1955 and is preferred universally. But it fails to control surgical site infection which is a major post operative complication.. Chlorhexidine alcohol has been widely used as an oral antiseptic solution and its efficacy has been recently made it as an antiseptic and disinfectant ${ }^{2}$. This study compares the efficacy of Chlorhexidine-Gluconate $(2.5 \% \mathrm{v} / \mathrm{v})$ \& Isopropyl Alcohol (63\%) to Povidone-Iodine (5\%) in preventing surgical site infections in elective midline laparotomy surgeries.

Aim of Study: To compare the efficacy of chlorhexidine alcohol versus povidone iodine for pre-operative skin preparation in preventing surgical site infection in elective midline laparotomies.

Materials and Methods: A total of 200 patients were taken for this study. 100 patients underwent draping with chlorhexidine alcohol (Group A) who were compared with 100 patients who underwent draping with povidone iodine (Group B). Variables used in this study are wound infection and ASEPSIS score.

Results: In the povidone-iodine group 14 (14\%) patients had wound infection and in the chlorhexidine alcohol group 10(10\%) patients had wound infection. Even though SSI is lower in chlorhexidine group, the difference was not statistically significant (p value 0.384).

Conclusion: There is no significant difference between chlorhexidine alcohol and povidone iodine in preventing surgical site infection in elective midline laparotomy surgeries.

Keywords: Chlorhexidine Alcohol, Povidone Iodine, ASEPSIS score.
\end{abstract}

\section{Introduction}

Despite many advances in the surgical techniques in the past few years, postoperative wound sepsis still remains a major problem. Although, only occasionally a cause of mortality, it is a frequent cause of increased morbidity leading to prolonged hospitalisation of the patient. Surgical Site Infections are the third most commonly reported 
nosocomial infections all over the world ${ }^{1}$. Despite the advances made in preoperative asepsis, patients subjected to operations naturally have to face the risk of complications due to infections. Povidone-Iodine (5\%) is been used for preoperative skin preparation in surgeries since 1955 and is preferred universally. But even then a surgical site infection is a major complication it fails to control completely. Chlorhexidine alcohol has been widely used as oral antiseptic solution in mouth washes. Its increased efficacy has been recently made it as an antiseptic and disinfectant ${ }^{2}$. This study compares the efficacy of Chlorhexidine-Gluconate (2.5\% v/v) \&Isopropyl Alcohol (63\%) to Povidone-Iodine $(5 \%)$ in preventing surgical site infections in elective midline laparotomy surgeries.

Patient's skin is a major source of pathogens that cause Surgical Site Infection. It is an established fact that the normal skin of healthy human beings harbors a rich bacterial flora ${ }^{7}$. Normally considered non-pathogenic, these organisms may be a potential source of infection of the surgical wound, making skin preparation at the time of the procedure critical ${ }^{8}$. There are several kinds of antiseptics available for preoperative skin preparation, however povidone iodine and chlorhexidine alcohol are commonly used in clinical practice. The present study was undertaken to compare and evaluate the efficacy of chlorhexidine alcohol versus povidone iodine in elective midline laparotomy surgeries for prevention of surgical site infections.

\section{Aim of Study}

To compare the efficacy of chlorhexidine alcohol versus povidone iodine for pre-operative skin preparation in preventing surgical site infection in elective midline laparotomies.

\section{Materials and Methods}

This is a Comparative study conducted in Dept. of Surgery in a tertiary care center Kerala over a period of $1 \frac{1}{2} 2$ year starting from Jan 2016 with a sample size of 200. All those patients are admitted to General surgical wards in Department of Surgery and are posted for elective midline laparotomy surgeries between Jan 2016 to June 2017.

\section{Inclusion Criteria}

- Patient older than 18yrs.

- Patients undergoing elective midline laparotomy.

- Duration of surgery $30 \mathrm{~min}$ to $4 \mathrm{~h}$.

\section{Exclusion Criteria}

- Patients undergoing emergency surgery.

- Immuno compromised patients (HIV).

- Patients on long term steroids.

- Patients with focus of infection somewhere on the body.

- Patients undergoing chemotherapy or radiotherapy.

- Diabetic patients with poor glycemic control (HbA1c>9).

- Patients with history of allergy to study agents.

The patients are divided into two groups by computer randomization that is Group A (chlorhexidine alcohol group) and Group B (povidone iodine group). All cases are elective surgeries done under is General Anaesthesia. All patients received one dose of parenteral antibiotics 1 hour prior to applying incision and a course of parenteral antibiotic post operatively. All cases are opened using a vertical midline laparotomy incision. For all patients, rectus was closed in the midline using No.1 loop PDS thus apposing the wound edges. Then the wound was closed by skin staples.

The agents used for the study are $2.5 \% \mathrm{v} / \mathrm{v}$ chlorhexidine in $63 \% \mathrm{v} / \mathrm{v}$ isopropyl alcohol and povidone iodine $5 \%$. The antiseptics agents will be applied to the skin by sterile gauze under aseptic precaution. The antiseptics were left on the skin for three to four minutes. Post operatively the same agent which was used for draping will be applied to the sutured surgical wound by sterile gauze. The surgical wounds will be examined daily until the patient is discharged from the hospital and patients will be followed up weekly for a 
period of 30 days. In this study ASEPSIS scoring system will be used for assessment of surgical site wound infection.

The data is collected and results are analysed using SPSS version 18.0. Quantitative variables were expressed as the mean \pm standard deviation. Comparison of means was done by student' $t$ ' test, values without mean was compared by Pearson chi square test.

\section{Observation and Discussions}

In this study we compared the effects of Chlorhexidine-Gluconate $(2.5 \% \mathrm{v} / \mathrm{v})$ \&Isopropyl Alcohol (63\%) to Povidone-Iodine (5\%) in preventing surgical site infections in elective midline laparotomy surgeries. Surgical site infection in chlorhexidine group (10\%) was found to be lower than the povidone iodine group (14\%) which is in accordance with the study conducted by Rabih O Darouiche et $\mathrm{al}^{8}$ where the incidence of surgical site infection was $9.5 \%$ in chlorhexidine alcohol group $16.1 \%$ in betadine group. In another study conducted by Geetha Danasekaran et $\mathrm{al}^{83}$ surgical site infection in chlorhexidine alcohol group was $3.3 \%$ and in povidone iodine group it was $23.33 \%$. No significant statistical difference of the risk factors between the two groups of the sample patients such as age, operative time, wound classification or underlying host factors. Staphylococcus aureus (6\% in chlorhexidine alcohol group and $12 \%$ povidone iodine group) was the commonest organisms isolated. After the application of antiseptic agents, there was reduction of bacterial colonisation in both the groups. These findings were similar to the results of a study done in Thailand. The study reported that wound infection decreased from $3.2 \%$ to $2 \%$ after chlorhexidine skin preparation and the organisms found in the culture specimen included Staphylococcus epidermidis, Staphylococcus aureus, Streptococcus species and Enterococcus species. In this study, among the patients who has SSIs, the microbiological examination revealed E.coli as the organism $(3.33 \%)$ present in chlorhexidinealcohol group. In povidone-iodine group of the patients had infection due to Staphylococcus aureus $(16.66 \%)$ followed by E. coli $(6.6 \%)$. In the present study, majority $(85 \%)$ of the patients in chlorhexidine alcohol had duration of hospital stay up to seven days and $11 \%$ patients required hospital stay between 8 to 14 days. In povidone iodine group, $79 \%$ patients had hospital stay up to seven days followed by $14 \%$ of patients between 8 to 14 days and $7 \%$ of patients more than 14 days suggesting prolonged length of hospital stay in povidone iodine group. The mean length of hospital stay in chlorhexidine alcohol group was $7.43 \pm 2.58$ days, whereas in povidone iodine, it was $8.02 \pm 3.17$ days. In the present study, postoperative day wound inspection findings revealed high rate of surgical site infection in povidone iodine group (14\% versus $10 \%)$ but the difference is not statistically significant ( $\mathrm{p}$ value 0.079).

Table 1: Type of elective surgery

\begin{tabular}{|l|c|c|c|}
\hline Elective surgery & Chlorhexidine alcohol & Povidone-iodine & Total \\
\hline Esophagogastric & $11(11 \%)$ & $6(6 \%)$ & 17 \\
\hline Hepatobiliary & $29(29 \%)$ & $21(21 \%)$ & 50 \\
\hline Small intestine & $30(30 \%)$ & $47(47 \%)$ & 77 \\
\hline Colorectal & $30(30 \%)$ & $26(26 \%)$ & 56 \\
\hline Total & 100 & 100 & 200 \\
\hline
\end{tabular}

Table 2: Diabetes

\begin{tabular}{|l|c|c|c|}
\hline Diabetes & Chlorhexidine alcohol & Povidone-iodine & Total \\
\hline Diabetic & 8 & 6 & 14 \\
\hline Non diabetic & 92 & 94 & 186 \\
\hline Total & 100 & 100 & 200 \\
\hline
\end{tabular}


Table 3: Smoking

\begin{tabular}{|l|l|l|l|}
\hline Smoking & Chlorhexidine alcohol & Povidone-iodine & Total \\
\hline Smokers & 12 & 11 & 23 \\
\hline Non smokers & 88 & 89 & 177 \\
\hline Total & 100 & 100 & 200 \\
\hline
\end{tabular}

Table 4: Surgical site infection

\begin{tabular}{|l|l|l|l|}
\hline SSI & Chlorhexidine alcohol & Povidone-iodine & Total \\
\hline Present & 10 & 14 & 24 \\
\hline Absent & 90 & 86 & 176 \\
\hline Total & 100 & 100 & 200 \\
\hline
\end{tabular}

Table 5: Types of surgical site infections

\begin{tabular}{|l|c|c|c|}
\hline Type & Chlorhexidine alcohol & Povidone-iodine & Total \\
\hline Superficial & 9 & 13 & 22 \\
\hline Deep & 1 & 1 & 2 \\
\hline No infection & 90 & 86 & 176 \\
\hline Total & 100 & 100.0 & 200 \\
\hline
\end{tabular}

Table 6: Asepsis score

\begin{tabular}{|l|c|c|c|}
\hline Score & Chlorhexidine alcohol & Povidone-iodine & Total \\
\hline $0-10$ & 90 & 84 & 174 \\
\hline $11-20$ & 6 & 10 & 16 \\
\hline $21-30$ & 4 & 6 & 10 \\
\hline Total & 100 & 100 & 200 \\
\hline
\end{tabular}

Table 7: Type of organism

\begin{tabular}{|l|c|c|c|}
\hline Type of organism & Chlorhexidine alcohol & Povidone-iodine & Total \\
\hline Staphylococci & 6 & 12 & 18 \\
\hline E coli & 4 & 4 & 8 \\
\hline Sterile & 90 & 84 & 174 \\
\hline Total & 100 & 100.0 & 200 \\
\hline
\end{tabular}

Table 8: Hospital stay

\begin{tabular}{|l|c|c|c|}
\hline Hospital stay in days & Chlorhexidine alcohol & Povidone-iodine & Total \\
\hline Up to 7 & 85 & 79 & 164 \\
\hline $8-14$ & 11 & 14 & 25 \\
\hline$>14$ & 4 & 7 & 11 \\
\hline Total & 100 & 100 & 200 \\
\hline
\end{tabular}

\section{Conclusion}

There is no significant difference between chlorhexidine alcohol and povidone-iodine in preventing surgical site infection in elective midline laparotomies.

\section{Acknowledgements: Nil}

Source of Support in the form of grants: Nil

\section{References}

1. Patel NP. Antimicrobial Agents for Surgical Infections. Surg Clin of North Am April2009;89:365-90.

2. Brunicardi CF. Surgical Infections. Schwartz's Principles of Surgery, McGraw Hill Company, $9^{\text {th }}$ International edition, 2010p.132-88.

3. Noorani A, Rabey N, Walsh SR, Davies RJ. Systematic review and meta-analysis of preoperative antisepsis with 
chlorhexidine alcohol versus povidoneiodine in clean-contaminated surgery. $\mathrm{Br} \mathrm{J}$ Surg. 2010; 97(11):1614-162.

4. Dumville JC, McFarlane E, Edwards P, Lipp A, Holmes .A Preoperative skin antiseptics for preventing surgical wound infections after clean surgery. Cochrane Database Syst Rev2013, Issue 3. Art. No.: CD003949

5. Patil RA,Gaikwad VV,Kulkarni RM. A Comparative Study Of chlorhexidine alcohol Versus Povidone-Iodine For Surgical Site Antisepsis In Clean \& Clean Contaminated Cases. Journal of Medical Thesis 2013 July -Sep; 1(1):33-34

6. Darouiche RO, Wall MJ Jr, Itani KM, Otterson MF, Webb AL, Carrick MM, et al. chlorhexidine alcohol versus PovidoneIodine for Surgical-Site Antisepsis N Engl J Med. 2010 Jan 7; 362(1):18-26

7. 7Shooter RA, Taylor GW, Ellis G, et al. Postoperative wound infection. Surgery Infect Dis ObstetGynecol1956;103(3):257262.

8. Horan TC, Gaynes RP, Martone WJ. CDC definitions of nosocomial surgical site infections, 1992: a modification of CDC definitions of surgical wound infections. Infect Control Hospepidemiol 1992;13 (10):606-608.

9. Langgartner $\mathrm{J}$, Linde $\mathrm{HJ}$, Lehn $\mathrm{N}$, et al. Combined skin disinfection with chlorhexidine alcohol/propanol and aqueous povidone-iodine reduces bacterial colonization of central venous catheters. Intensive Care Med 2004;30(6):10811088.

10. Hemani ML, Lepor H. Skin preparation for the prevention of surgical site infection: which agent is best? Rev Urol 2009;11(4):190-5.

11. Darouiche RO, Wall MJ Jr, Itani KM, Otterson MF, Webb AL, Carrick MM, et al. Chlorhexidine alcohol-alcohol versus povidone-iodine for surgical-site antisepsis. N Engl J Med 2010;362(1):1826.

12. Plowman R, Graves N, Griffin MA, et al. The rate and cost of hospital-acquired infections occurring in patients admitted to selected specialties of a district general hospital in England and the national burden imposed. J Hosp Infect 2001;47:198-209.

13. Culligan PJ, Kubik K, Murphy M, et al. A randomized trial that compared povidone iodine and chlorhexidine as antiseptics for vaginal hysterectomy. Am J ObstetGynecol 2012;192(2):422-425.

14. Danasekaran G, Rasu S, Palani M. A study of comparative evaluation of preoperative skin preparation with chlorhexidine-alcohol versus povidoneiodine in prevention of surgical site infections. Journal of Evidence based Medicine and Health Care 2017; 4 (4): 2453-2460.

15. Lynch W, Davey PG, Malek M, et al. Cost-effectiveness analysis of the use of chlorhexidine alcohol detergent in preoperative whole-body disinfection in wound infection prophylaxis. J Hosp Infect1992;21:179-91.

16. Webster J. Preoperative bathing or showering with skin antiseptics to prevent surgical site infection. Cochrane Database of Syst Rev2007;(2):CD004985. 